\title{
Una especie nueva notable de Pinguicula (Lentibulariaceae) de los estados de Querétaro y San Luis Potosí, México
}

\author{
Sergio Zamudio Ruiz \\ Instituto de Ecología, A.C., Centro Regional del Bajío, Apartado Postal 386, 61600 Pátzcuaro, Michoacán
}

\begin{abstract}
Resumen. Se describe Pinguicula calderoniae como especie nueva para la ciencia. La planta habita sobre laderas de rocas calizas, en el bosque mesófilo de montaña de la Sierra Madre Oriental, en el límite de los estados de Querétaro y San Luis Potosí. Por la corola bilabiada, con tubo largamente infundibuliforme, igual en longitud o un poco más corto que el espolón, se ubica en el subgénero Pinguicula, sección Longitubus. Las "hojas de verano" lanceolado-lineares la distinguen claramente de los demás miembros de la sección.

Palabras clave: Pinguicula, Lentibulariaceae, taxonomía.

Abstract. Pinguicula calderoniae is described as a new species to science. It grows on calcareous rocks in the cloud forest in the border of Querétaro and San Luis Potosí states. On account of its bilabiate corolla with long-infundibuliform tube, as long as or shorter than the spur, it is placed in subgenus Pinguicula, section Longitubus. This new taxon is clearly differentiated from other members of this group by its long lanceolatelinear summer leaves, which are unique in the section.
\end{abstract}

Key words: Pinguicula, Lentibulariaceae, Taxonomy.

E xploraciones recientes realizadas en algunos valles intermontanos de la Sierra Madre Oriental, en el límite entre los estados de Querétaro y San Luis Potosí, han conducido al descubrimiento de una nueva especie del género Pinguicula. Las plantas con flores bilabiadas, rojo-purpúreas y largas hojas lanceoladolineares muestran una combinación de caracteres tan novedosa que no hay duda de que se trata de una especie nueva, que se describe a continuación.

Pinguicula calderoniae Zamudio, sp. nov. (figura 1)

Herba perennis. Folia radicalia rosulata integerrima biformia; rosula hiemis hypogaea $5-15 \mathrm{~mm}$ diametro bulbiformis ex foliis numerosis (6-30) composita, foliis squamiformibus obtrullatis vel ellipticis apice obtusis mucronatis glabriusculis $3-10 \mathrm{~mm}$ longis, $1.5-4 \mathrm{~mm}$ latis; rosula aestatis (3) 4-8 foliis erectis composita, foliis lineari-lanceolatis, proximaliter distaliterque gradatim attenuatis, superne glandulis sessilibus dense vestitis et glandulis stipitatis modice dense vestitis, (60) 80$260 \mathrm{~mm}$ longis, $3-8.5 \mathrm{~mm}$ latis margine valde revolu- tis. Pedunculi 1-3, erecti, glandulis stipitatis obsiti, 60$150 \mathrm{~mm}$ alti, uniflori. Flores $20-35 \mathrm{~mm}$ longi (calcari incluso). Calyx bilabiatus extus glandulis stipitatis obsitus; labio supero usque ad basim trilobo, lobis lanceolatis vel triangulatis; labio infero bilobo, lobis usque ad 1/4-1/2 longitudinis divisis, lanceolatis vel triangulatis. Corolla bilabiata rubro-purpurea extus glandulis stipitatis dispersis obsita, lobis oblongis vel anguste oblongis, obtusis vel rotundatis $5-8 \mathrm{~mm}$ longis, 3-6 $\mathrm{mm}$ latis. Tubus longe infundibuliformis, albus vel ex purpureo albus $7-10 \mathrm{~mm}$ longus, intus pilosus basim tubi versus pilis brevioribus. Calcar 7$16 \mathrm{~mm}$ longum. Stamina 2-2.5 $\mathrm{mm}$ longa; pollen (4) 5(6)-colporatum. Ovarium subglobosum glandulis stipitatis dispersis obsitum. Stigma violaceum bilabiatum, labio infero suborbiculato dentato. Capsula subglobosa 3-4 $\mathrm{mm}$ diametro. Semina fusiformia \pm 1 $\mathrm{mm}$ longa $\pm 0.25 \mathrm{~mm}$ lata, alveolata.

TIPO: México, Querétaro. Municipio de Landa; extremo norte del Llano Chiquito, 14.VI.2000, S. Zamudio, G. Ocampo y A. Reznicek 11421 (Holotipo: IEB). 
Plantas herbáceas perennes. Hojas basales dimorfas, agrupadas en dos rosetas subsecuentes; roseta de invierno hipogea, compacta en forma de bulbo o más o menos abierta, subesférica u ovada, de 5 a $15 \mathrm{~mm}$ de diámetro, formada por (6)8 a 20(30) hojas crasas, obtruladas a elípticas en contorno, mucronadas, aquilladas en el dorso, esparcidamente glandular pubescentes en el haz o glabras, de 3 a $10 \mathrm{~mm}$ de largo, por 1.5 a $4.0 \mathrm{~mm}$ de ancho; "roseta de verano" laxa, formada por (3) 4 a 8 hojas membranáceas, erectas, lanceolado-lineares, de (60)80 a $260 \mathrm{~mm}$ de largo, por 3 a $8.5 \mathrm{~mm}$ de ancho, atenuadas en ambos extremos, margen revoluto, glandular-pubescentes en el haz con glándulas capitadas muy cortas, densamente cubierta con glándulas sésiles translúcidas. Pedúnculos 1 a 3 , rollizos, de 60 a $150 \mathrm{~mm}$ de largo, esparcidamente glandular-pubescentes. Flores de 20 a $35 \mathrm{~mm}$ de largo (incluyendo el espolón); cáliz bilabiado, el la- bio superior dividido casi hasta la base en tres lóbulos lanceolados a triangulares, de 2 a $3.5 \mathrm{~mm}$ de largo, por 1 a $2.0 \mathrm{~mm}$ de ancho, unidos $1 \mathrm{~mm}$ en la base, labio inferior bilobado en $1 / 4$ o $1 / 2$ de su longitud, lóbulos lanceolados a triangulares, de 1 a $2 \mathrm{~mm}$ de largo, por 1 a $1.5 \mathrm{~mm}$ de ancho, unidos 1 a $2 \mathrm{~mm}$ en la base. Corola bilabiada, rojo-purpúrea, cubierta en la parte externa con glándulas estipitadas esparcidas; labio superior bilobado, los lóbulos oblongos a angostamente oblongos, obtusos a redondeados en el ápice, de 5 a $8 \mathrm{~mm}$ de largo, por 3 a $6 \mathrm{~mm}$ de ancho; labio inferior un poco más grande que el superior, trilobado, lóbulos oblongos a angostamente oblongos, truncados o redondeados en el ápice, de 5 a $9 \mathrm{~mm}$ de largo, por 2.5 a $6 \mathrm{~mm}$ de ancho; tubo largamente infundibuliforme, de 7 a $10 \mathrm{~mm}$ de largo, blanco o ligeramente teñido de púrpura, piloso en su interior con pelos multicelulares, cilíndrico-

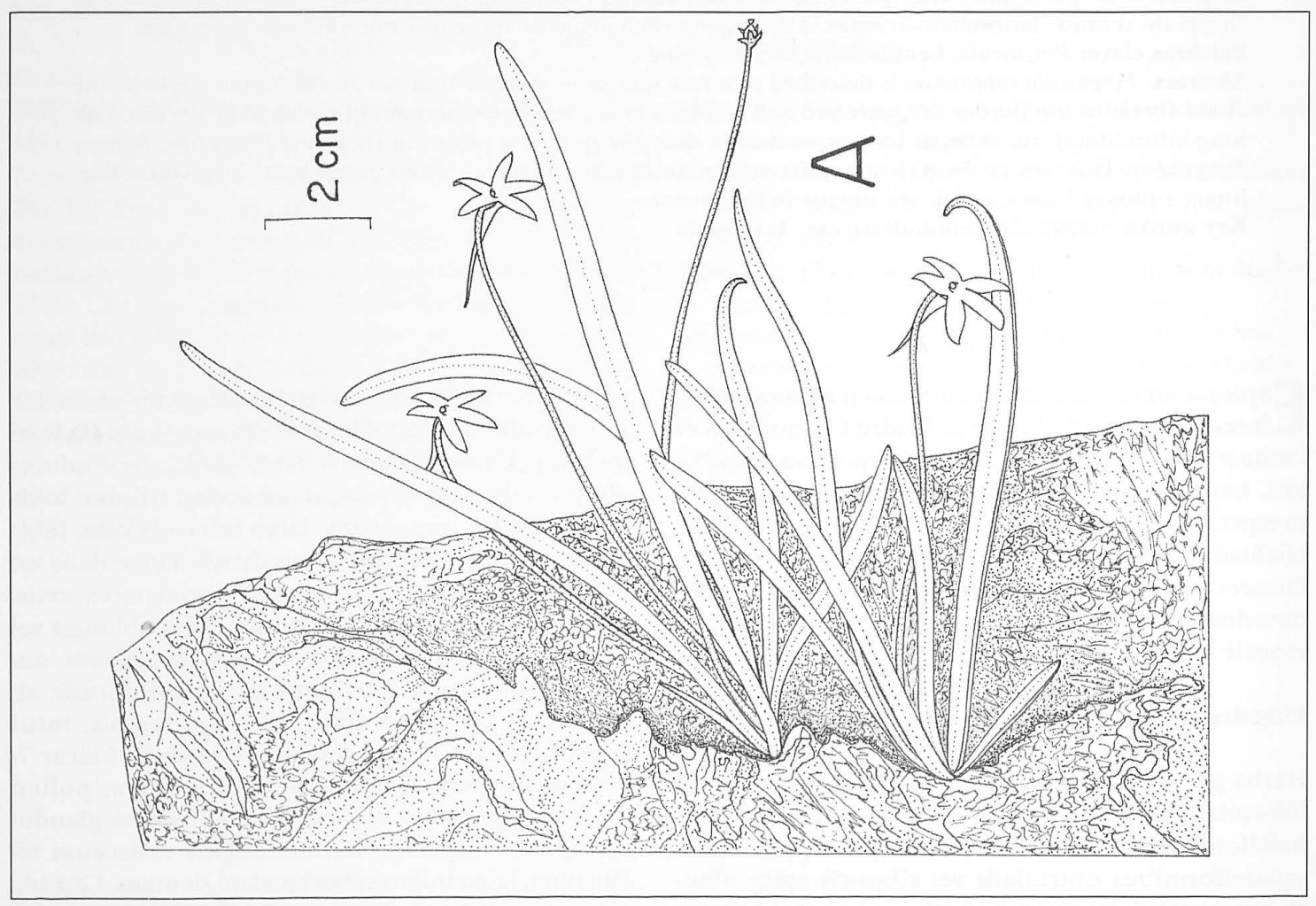

Figura 1. Pinguicula calderoniae. A. Hábito de la planta en floración; B. Serie de hojas de verano; C. Corola vista de frente con lóbulos angostos; D. Corola vista de frente con lóbulos anchos; E.Vista posterior de la corola mostrando el tubo largamente infundibuliforme; F. Cáliz; G. Pelos del interior del tubo de la corola; H. Pelos del interior del espolón; I. Roseta de invierno compacta; J. Serie de hojas de invierno de la roseta compacta; K. Roseta de inviemo abierta; L. Serie de hojas de invierno de la roseta abierta. Dibujo de Rogelio Cárdenas. 
EUna especie nueva notable de Pinguicula (Lentibulariaceae) de los estados de Querétaro y San Luis Potusí, México

subulados, los que se observan más cortos hacia la base del tubo; espolón igual o más largo que el tubo, de 7 a $16 \mathrm{~mm}$ de largo. Estambres de 2 a $2.5 \mathrm{~mm}$ de largo, polen (4)-5-(6)-colporado. Ovario subgloboso, cubierto con glándulas estipitadas esparcidas, estigma bilabiado, labio inferior suborbicular. Cápsula subglobosa, de 3 a $4 \mathrm{~mm}$ de diámetro. Semillas numerosas, fusiformes, de $\pm 1 \mathrm{~mm}$ de largo y $\pm 0.25 \mathrm{~mm}$ de ancho, alveoladas.

\section{Distribución y ecología}

Hasta ahora sólo se conoce de dos localidades cercanas de la Sierra Madre Oriental, en la porción limítrofe entre los estados de Querétaro y San Luis Potosí. Crece sobre concreciones de carbonato de calcio, en riscos o paredes verticales, en las grietas de rocas calizas, en sitios muy húmedos del bosque mesófilo de montaña, entre 2200 y $2300 \mathrm{~m}$ de altitud.

\section{Fenología}

Se ha colectado en floración en el mes de junio, con rosetas de verano jóvenes y restos de la roseta de invierno. En plantas cultivadas se observó que el desarrollo de la roseta de verano se continúa hasta octubre y en noviembre se forma la roseta de invierno; ésta es compacta, con forma de bulbo y permanece enterrada, protegida por una capa de hojas secas de consistencia escariosa, hasta mayo del siguiente año.

Ejemplares adicionales examinados. México, San Luis Potosí. Municipio de Xilitla; Llano del Conejo, 14.VI.2000, S. Zamudio, G. Ocampo y A. Reznicek 11431 (IEB).

Etimologia. El nombre de la especie se dedica a la Maestra Graciela Calderón de Rzedowski, destacada botá-
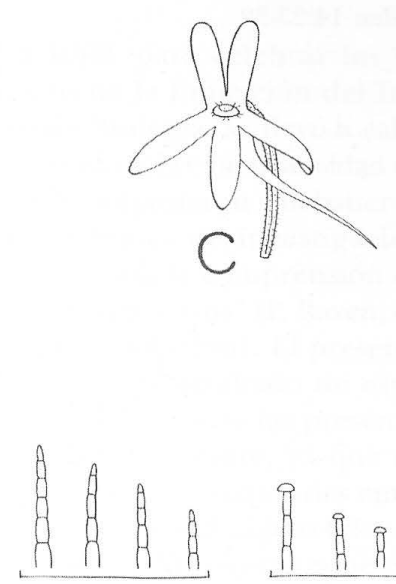

G

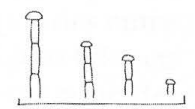

$H$
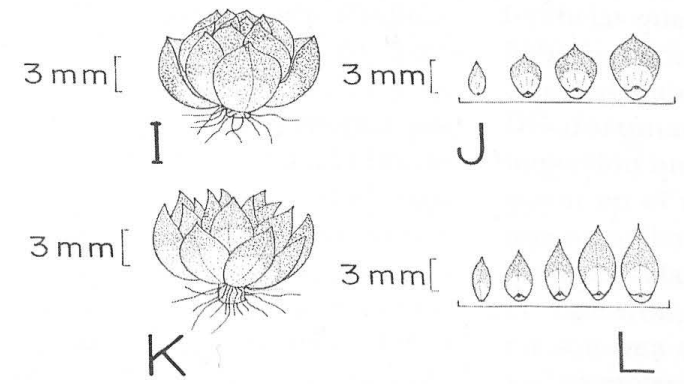
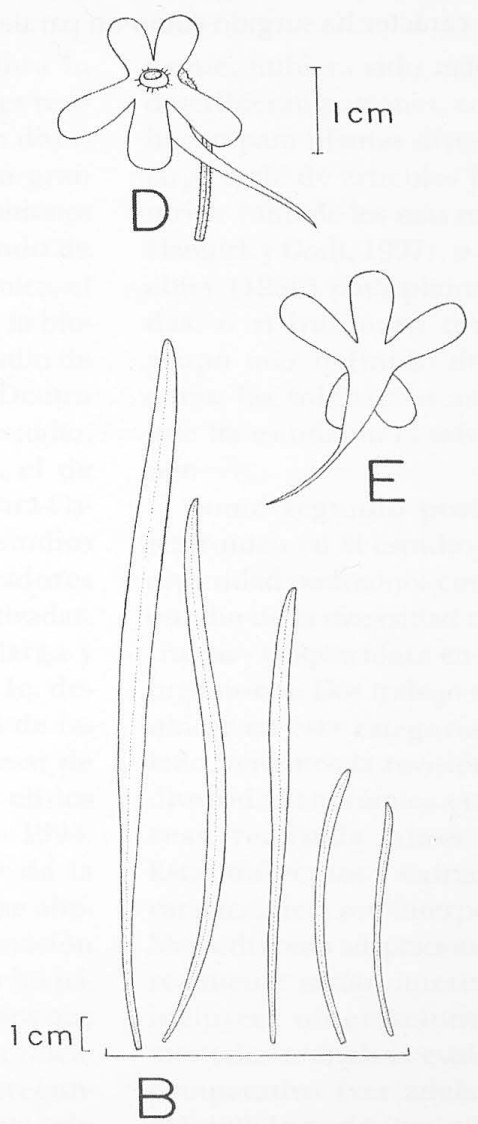
nica mexicana quien ha hecho un aporte trascendental al conocimiento de la flora de México.

\section{Discusión}

Por la corola rojo-purpúrea, claramente bilabiada, el tubo largo, infundibuliforme y el espolón igual en longitud o más largo que el tubo, Pinguicula calderoniae se ubica en la sección Longitubus del subgénero Pinguicula, de la que hasta ahora se conocían sólo cuatro especies (Zamudio y Rzedowski, 1991). Dentro de esta sección la nueva especie se puede diferenciar con facilidad de las demás por las hojas de verano lanceolado-lineares, carácter que no existe en ninguna otra especie del grupo. También la distinguen la forma de la "roseta de invierno" y las hojas crasas obtruladas o elípticas en contorno, sólo parecidas a las de P. crassifolia (Zamudio, 1998), entre los miembros de esta sección.

Estas plantas muestran una combinación de caracteres novedosa para el grupo. La presencia de hojas lanceolado-lineares en Pinguicula calderoniae confirma que éste carácter ha surgido como un paralelismo evo- lutivo en varias especies de diferentes secciones de las Pinguicula mexicanas.

\section{Agradecimientos}

El autor agradece cumplidamente a Fernando Chiang Cabrera y a Rosa María Murillo la revisión crítica del manuscrito y sus atinadas observaciones, a Gilberto Ocampo y Anton A. Reznicek su ayuda en la colecta de ejemplares botánicos. Este trabajo ha sido realizado con apoyo económico del Instituto de Ecología, A.C. (cuenta 902-03), del Consejo Nacional de Ciencia y Tecnología, así como de la Comisión Nacional para el Conocimiento y Uso de la Biodiversidad.

\section{Literatura Citada}

Zamudio, S. 1998. Dos nuevas especies de Pinguicula (Lentibulariaceae) del centro y norte de México. Acta Bot. Mex. 3:21-28.

Zamudio, S. y J. Rzedowski. 1991. Dos especies nuevas de Pinguicula (Lentibulariaceae) del estado de Oaxaca, México. Acta Bot. Mex. 14:23-32. 